\title{
The Platonic sage in love
}

\author{
John Dillon
}

\begin{abstract}
This article explores the nature of the erotic impulse set forth in Diotima's speech in Plato's Symposium, and in the myth of the Phaedrus, with a view to deciding how far Plato intends it to be a purely selfish process. After all, in the 'ladder of ascent' to the Beautiful Itself in Symp. 210-12, the individual beloved seems to be left behind, and even disdained, and Plato has been criticised for this, by such authorities as Gregory Vlastos. I argue that this cannot really have been Plato's intention, and adduce the later Platonist discussion about the proper form that a philosophic love-affair should take.
\end{abstract}

Love, as we know, in Greek thought (as, I suppose, in most other thought), is habitually regarded as an irrational force. Objectified as the goddess Aphrodite, or her follower and agent (only sometimes son) Eros, it is presented by poets and moralists as a form of madness or intoxication that may strike almost at random, leading the most sensible persons to do the most foolish things. The lines of the lyric poet Ibycus are often quoted in this connexion (Fr. 2 Bergk / 287 Campbell):

"Again Love, looking at me meltingly

from under his dark eyelids,

hurls me with his manifold enchantments

into the boundless nets of the Cyprian.

How I fear his onset,

as a prize-winning horse, now old, but still yoke-bound, goes, all unwillingly, with swift chariot to the race."

This is a lively portrayal of what was the conventional poetic (and educated layman's) view of love. It is notable that we have this passage of Ibycus because Plato himself makes the philosopher Parmenides refer to it ${ }^{1}$ in his dialogue of that name, as a preface to Parmenides' overtly unwilling embarkation upon the eminently philosophical activity of dialectic. But Plato's very use of it serves to point up the contrast between the behaviour proper to a philosopher and that characteristic of a poet, or non-philosopher in general. Parmenides here, with ironic hesitation, gives way to an essentially rational impulse, while borrowing the words of one giving way to an irrational one, such as a true philosopher should never yield to.

Another famous passage is the ode to Eros in Euripides' Hippolytus, in the context of the revelation of Phaedra's disastrous infatuation with her stepson. The first stanza runs as follows (525-32):

"Love, Love, you that upon the eyes

distill longing, bringing sweet delight

into the souls of those against whom you campaign,

never may you manifest yourself to me to my hurt,

nor ever come discordant.

For the shafts neither of fire nor of the stars

surpass that of Aphrodite launched from the hand

of Eros, the child of Zeus."2

\footnotetext{
${ }^{1}$ The actual text is only quoted in a scholion to the passage (p. 49 Greene), and by Proclus in his commentary (In Parm. 1028 Cousin).

2 Other instances of Eros' darts in Euripides are Medea 530-1 and Iphigenia in Aulis 548-9; of darts sent by Aphrodite herself, Medea 634-5.
} 
Here the example of the unfortunate Phaedra emphasises the total irrationality, and indeed malignity, of the force of love, justifying Sophocles' remark reported by old Cephalus in Book I of Plato's Republic (329C), when he was asked if he could still make love to a woman: "Quiet, man! It is to my great delight that I have broken free of that, like a slave who has escaped from a mad and savage master."

How, then, one may ask, can the true philosopher have any truck with the passion of love? It is a basic axiom of Plato's ethics, after all, that the irrational part, or aspect, of the soul, including the erotic impulse, should be subordinated to the reason, and that the passions, if not entirely eradicated, should at all times be reduced to 'moderation' by the exercise of the power of rationality. ${ }^{3}$ On the other hand, though, it is notoriously the case that at least a sublimated form of erōs is presented by Plato in a number of dialogues, notably the Symposium and the Phaedrus, as the driving force behind all true philosophic communication. How is this contradiction to be resolved? And how sublimated does the erotic impulse have to be before it is deemed compatible with the philosophic outlook?

It does seem probable that Plato himself, like his master Socrates before him, was subject to strong erotic impulses, which, rather than rejecting and attempting to repress out of hand, he sought to harness to some purpose compatible with the exercise of the activity proper to a philosopher. The man, after all, who composed the mythologized description of falling in love in the Phaedrus (251A-E) has surely experienced what he is talking about. Despite its length, I feel that the passage is worth quoting in full:

"But the newly initiated, who has had a full sight of the celestial vision, when he beholds a godlike face or a physical form which truly reflects ideal beauty, first of all shivers and experiences something of the dread which the vision itself inspired; next he gazes upon it and worships it as if it were a god, and, if he were not afraid of being thought an utter madman, he would sacrifice to his beloved as to the image of a divinity. Then, as you would expect after a cold fit, his condition changes, and he falls into an unaccustomed sweat; he receives through the eyes the emanation of beauty, by which the soul's plumage is fostered, and grows hot, and this heat is accompanied by a softening of the passages from which the feathers grow, passages which have long been parched and closed up, so as to prevent any feathers from shooting. As the nourishing moisture falls upon it the stump of each feather under the whole surface of the soul swells and strives to grow from its root; for in its original state the soul was feathered all over. So now it is all in a state of ferment and throbbing; in fact the soul of a man who is beginning to grow his feathers has the same sensation of pricking and irritation and itching as children feel in their gums when they are just beginning to cut their teeth.

When in this condition the soul gazes upon the beauty of its beloved, and is fostered and warmed by the emanations which flood in upon it - which is why we speak of a 'flood' of longing - it wins relief from its pain and is glad; but when it is parched by separation the openings of the passages where the feathers shoot close up through drought and obstruct the development of new growth. Imprisoned below the surface together with the flood of longing of which I have spoken, each embryo feather throbs like a pulse and presses against its proper outlet, so that the soul is driven mad by the pain of the pricks in every part, and yet feels gladness because it preserves the memory of the beauty of its darling. In this state of mingled pleasure and pain the sufferer is perplexed by the strangeness of his experience and struggles helplessly; in his frenzy he cannot sleep at night or remain still by day, but his longing drives him wherever he thinks he may see the possessor of beauty. When he sees him and his soul is refreshed by the flood of emanations, the closed passages are unstopped; he obtains a respite from his pains and pangs, and there is nothing to equal the sweetness of the pleasure which he enjoys for the moment." (tr. Hamilton)

3 This is most clearly stated in various passages of the Republic, notably IV 441C-445E and IX 588B592B. 
This, as we see, is a description of violent emotion, but also of the control and sublimation of violent emotion. ${ }^{4}$ This is reinforced by the description which we find some pages later of the violent repression of the 'unruly horse' of the soul (253E$254 \mathrm{E})$. It is perhaps the most vivid description in Greek literature of the workings of sexual desire, and, one feels, could only have been penned by one who is writing on the basis of bitter experience. Of course, in the scenario which Plato presents to us, the unruly horse is repressed, but only at considerable psychological cost.

The hope which Plato entertains is that, when a lover has demonstrated proper self-control, along with solicitude for the beloved's spiritual (and, no doubt, material) welfare, the beloved will experience a reaction of gratitude and affection (255B-D), which Plato characterizes as anterōs. In these circumstances, Plato is prepared to recognize that, just occasionally, in the case of a lover who is more of a timocrat than a philosopher proper, after a few drinks, sexual relations may take place (256B-D). Plato does not approve of this, though he is prepared to tolerate it as a kind of secondbest scenario; for the sage, though, there is to be no sex. A little cuddling, perhaps, and stroking of hair (we may think of Socrates stroking Phaedo's hair in the Phaedo), but definitely no sex.

I dwell on this, however, only to give a context to my remarks on the present occasion. I do not intend here to give a general discourse on Platonic love, on which much that is very sound has been already written over the years. ${ }^{5}$ What I want to do is rather to focus on two connected aspects of the Platonic theory of love which have come under fire in recent times from various distinguished authorities, to wit, the essential selfishness of the process, and its disregard for the individual as such, in favour of various types of highminded abstraction.

One might identify the root of the problem in Socrates' (and Diotima's) analysis, in Symposium 200Aff., of erōs as a sense of lack. In a sense, that it undoubtedly is, but the question is what it precisely is a lack of. The argument goes, as you recall, that Eros is of the beautiful and the good, and that it is of them because it lacks them. So then, if it lacks the beautiful and the good, it cannot itself be beautiful and good. But on the other hand we need not maintain that it is therefore ugly and bad; instead, it can be seen as intermediate between these two sets of opposites. And from this proposition emerges a whole fantasy about Eros being a daemon.

But in fact Socrates and Diotima should have been stopped at an earlier stage of their argument. Love, we may agree, involves a sense of lack, but it is not a lack of anything abstract or general; it is lack of something quite specific: the beloved him- or herself, or at least the bundle of qualities, physical and spiritual, embodied in the beloved. Once we start talking of love as a lack of the beautiful or the good in general, we are embarked on the rather treacherous ladder on which Plato would have us mount.

Let us consider the next stage of the argument. Diotima gets Socrates to agree (204Dff.) that the true aim of love is that 'the beautiful' ( $\tau \dot{\alpha} \kappa \alpha \lambda \dot{\alpha})$ and 'the good' ( $\tau \dot{\alpha}$

\footnotetext{
${ }^{4}$ E.g. the transformation of what is palpably a painful erection into a fantasy about the growing of feathers on the wings of the soul is most significant. For a good discussion, see A. W. Price, Love and Friendship on Plato and Aristotle, Appendix 2: Psychoanalysis looks at the Phaedrus.

${ }^{5}$ One may mention such works as John Gould's Platonic Love (London, 1963), or, earlier, Léon Robin's La théorie platonicienne de l'amour (Paris, 1933; 2nd. ed. 1964). More recently, there have been A. W. Price, Love and Friendship in Plato and Aristotle (Oxford, 1989), and Catherine Osborne, Eros Unveiled: Plato and the God of Love (Oxford, 1994) — though she ranges more widely, into patristics as well.
} 
$\dot{\alpha} \gamma \alpha \theta \dot{\alpha})$ should come into one's possession, so that, to sum up (206A), love may be defined as "desire for the perpetual possession of the good." Now this has been repeatedly criticised as being an entirely selfish aim. There seems to be no thought here of any benefit to the beloved; and, in a homosexual context, as this is, it is not envisaged that the love should be reciprocal (despite whatever degree of affection and respect a boy might develop for a noble and self-restrained lover), as it could well be in a heterosexual context, so that at least there would be a reciprocity of selfish aims.

Worse still, though, in the progression of philosophic love set out in the Symposium, it seems as though the individual is to be used only as a stepping stone to higher things. Let us consider Diotima's description of the ascent in 210Aff.:

"The man who would pursue the right way to this goal must begin, when he is young, by applying himself to the contemplation of physical beauty, and, if he is properly directed by his guide, he will first fall in love with one particular beautiful person and beget noble sentiments in partnership with him. Later he will observe that physical beauty in any person is closely akin to physical beauty in any other, and that, if he is to make beauty of outward form the object of his quest, it is great folly not to acknowledge that the beauty exhibited in all bodies is one and the same. When he has reached this conclusion he will become a lover of all physical beauty, and will relax the intensity of his passion for one particular person, because he will come to despise such a passion and

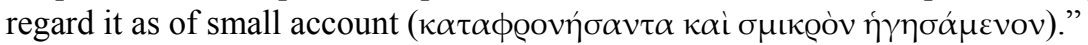

If we pause here to consider the story so far, and translate this into what we might call real terms, we get a pretty dismal picture. Leaving aside the tedium implied in the "begetting of noble sentiments" (hardly the most stimulating sort of love-talk, one would have thought), what are we to envisage being the response of the beloved to the philosophic lover's solemn contemplation of all other beautiful bodies that come into view, and his comparison, covert or overt, of these with that of his chosen beloved? One has a vision of the philosopher bringing his beloved to some suitably high-minded gathering - perhaps a lecture on Heidegger's later philosophy, or a concert of modern Classical music - and then proceeding to study the rest of the talent present with great enthusiasm, finally coming to look upon his chosen companion with relative disdain. Could any love affair long survive such a procedure?

But there is worse to come, from the beloved's point of view. The next stage is for the lover to disdain physical beauty altogether, and ascend, first, to the beauty manifested in soul, even if it is accompanied by a minimum of bodily beauty; and

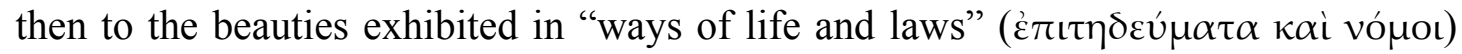
- whatever we may conceive these epitédeumata to be - and from that to the beauties of the sciences. ${ }^{6}$ So now the most beautiful thing in the room is the later philosophy of Heidegger or a Schoenberg String Quartet, and the original beloved is regarded henceforth with very scant appreciation. ${ }^{7}$ And we have not even yet attained to the highest point of the ascent. This is the "vast ocean of beauty", Beauty Itself, which makes all particular beauties, even those of the sciences, seem relatively trivial. Our philosophical lover has disappeared into the stratosphere.

I am being deliberately tendentious here, in order to bring out the basis of the modern romantic objection to Plato's concept of love. We must now ask ourselves, can it really be like that? Is the original beloved really no more than an object of

\footnotetext{
${ }^{6}$ We may note, by the way, that there is no mention, in the course of this ascent, of any appreciation of the beauties of nature. It would seem that Plato, like most Greeks of the Classical age, was more or less impervious to the charms of natural scenery.

7 Although, interestingly, Plato does not in fact provide any slot in his projecting ascent to the Beautiful for beauties either in the area of art and literature, or in that of nature. This has doubtless a good deal to do with his attitude to existing Greek art and literature, and with a more general Classical Greek disregard for the beauties of the natural world.
} 
exploitation, and a stepping-stone to higher things, to be disregarded when one has attained these? The answer, I think, has to be, no, it is not really like that at all. Plato would, indeed, be appalled to learn that his concept of love was seen as a selfish exploitation of the beloved. At the lowest level, he might say, love may well be like that, where a non-philosophic lover merely desires physical satisfaction from the body of his beloved; but what he himself is talking about is nothing physical, but rather the mutual bringing-to-birth, on the part of both lover and beloved, of noble sentiments and knowledge. Now this may sound pretty boring, even a sure-fire turnoff, but it is by no means selfish. Consider how he puts it at 209BC. He (or rather Diotima) has just been making the point that we are all of us pregnant with the desire to generate in a beautiful object offspring of one sort or another, that is to say, physical or spiritual, in order to secure a measure of immortality for ourselves. Those who simply desire physical offspring find themselves a woman, and have babies. Those who desire spiritual offspring, however, take a different direction:

"When by divine inspiration a man finds himself from his youth up spiritually fraught with these qualities, as soon as he comes of due age he desires to procreate and to have children, and goes in search of a beautiful object in which to satisfy his desire; for he can never bring his children to birth in ugliness."

So far, one must admit, it all sounds pretty self-centred, but it gets better:

"In this condition physical beauty is more pleasing to him than ugliness, and if in a beautiful body he finds also a beautiful and noble and gracious soul, he welcomes the combination warmly, and finds much to say to such a one about virtue and qualities and actions which mark a good man, and takes his education in hand."

Boring though this may sound, we must assume that the chosen beloved goes along with this programme; otherwise the whole enterprise does not reach first base. There is, therefore, a measure of cooperation and reciprocity assumed here.

"By intimate association with beauty embodied in his friend, and by keeping him always before his mind, he succeeds in bringing to birth the children he has long desired

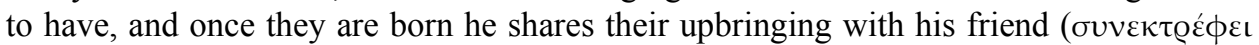

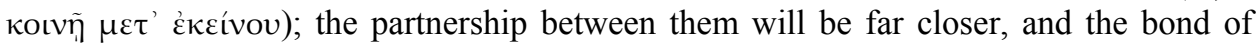
affection far stronger, than between ordinary parents, because the children that they share surpass human children by being immortal as well as beautiful. Everyone would prefer children such as these to children after the flesh."

We may be tempted to deride this whole scenario, but we cannot deny that it is envisaged by Plato as bringing a large measure of satisfaction to both partners in the relationship. And even if we concede that the beloved derives somewhat less benefit from it than the lover (certainly the relationship is not presented as a fully equal one - the lover paideuei the beloved, after all), we may assume that Plato sees the beloved as going on in due course to become a philosophic lover in his turn, and impose the same line of high-minded guff on some other beloved. And so the cycle will continue.

But, one might argue, even granting this degree of mutual satisfaction and benefit from the initial relationship, what about the rest of the philosophic ascent? Does this not inevitably leave the beloved behind? What about the telling phrase at

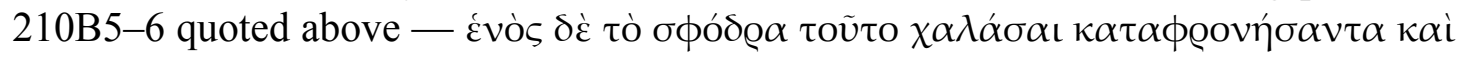

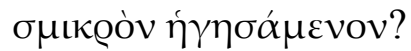

It is indeed commonly assumed that the ascent to Beauty Itself does leave the individual beloved behind, but I cannot persuade myself that Plato saw it this way. After all, it is the initial passion of love - and it is a passion (I ask you to cast your minds back to the passage of the Phaedrus that I quoted at the outset) - that launches the lover on his spiritual Odyssey. If he casts that aside at a later stage, he is attempting to perform the spiritual equivalent of the Indian rope trick, and it is not 
going to work. If he abandons his original beloved, after all, in favour of something more abstract, what then becomes of all the 'begetting in beauty' that is meant to go on in company with the beloved? You cannot really have a love-affair with the Laws of Solon or the right-angled triangle, after all.

No, the original stimulus, which provides the psychic energy for the ascent up the scala amoris, is the fixation on the original beautiful boy, and that cannot, it seems to me, be abandoned without the whole enterprise wilting. What I think happens is that it is that the original love is put in perspective - ideally with the intelligent cooperation of the beloved - and both lover and beloved embark on the ascent to higher forms of love, discussing the whole process animatedly throughout. The progressive sublimation of the original passion no doubt lessens somewhat its violence; after all, once the wings of the soul have grown again, they presumably cease to itch and ache as they did when they were first sprouting. ${ }^{8}$

On the whole, the failure that Plato can most justly be faulted for, in my view, is his apparent blindness to the original stimulus to falling in love with one particular beautiful body. That is the recognition - developed delightfully by Aristophanes in his earlier characterisation of love as the search for our 'other half', consequent on our having been sliced in two originally by Zeus - that what attracts us, from among the host of beautiful bodies which may present themselves to our gaze, is a peculiar combination of qualities, physical and spiritual, which creates what Goethe terms an 'elective affinity'. Diotima is actually made to 'correct' Aristophanes in the course of her speech $(205 \mathrm{E})$, by asserting that, contrary to 'a certain argument', we are not in search of our 'other half', unless that half happens also to be good - by which she wishes to mean the good in general. Of course the 'other half' is good in some sense, or one would not pursue it (that is possibly the point that Aristophanes wanted to make when he tries unsuccessfully to intervene at the end of the speech, at 212C), and Diotima contrives to sidestep this fact by generalising and objectifying the concept 'good', which is what we saw her doing at the beginning, when she identified love as a lack of the beautiful and the good. So in this way love specifically for an individual is undercut by virtue of what amounts to a sophistical sleight of hand, and it is asserted that what we are really in love with all the time is 'the good' in general. This seems to me a deep-rooted weakness in Plato's concept of love, which leads to farreaching consequences, such as have exposed him to much criticism. The sad thing is that there is really no reason why the scala amoris would not work just as well if based on a proper appreciation of the unique value of the individual beloved; but we must accept that that would be profoundly alien to Plato's system of thought.

Another odd feature of Platonic love-making is the notion of begetting beautiful thoughts in company with the beloved. Here Diotima employs an interesting mix of male and female generative processes, to produce a situation where the lover himself

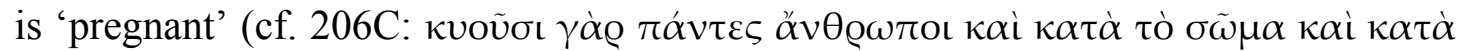
$\tau \grave{\eta} v \psi v \chi \eta \dot{v})$, and desires to bring something to birth. In this situation, the beloved, rather than being a receptacle for seed, is, as it were, a midwife, and becomes a sort of foster-parent of the spiritual offspring - which nonetheless he is expected to cherish, as having had a hand in.

\footnotetext{
${ }^{8}$ If further proof were needed of the survival of a beloved, whether the original one or some fortunate successor, one could appeal to the telling phrase from near the climax of Diotima's exposition (211B5-

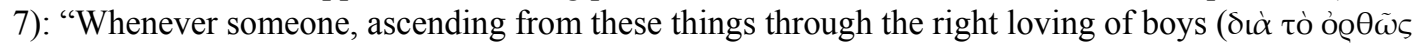
$\pi \alpha \iota \delta \varepsilon \varrho \alpha \sigma \tau \varepsilon \tilde{\imath} v)$ begins to see that Beauty, he would be almost touching the goal." This surely implies that a boy is still being loved, even at this exalted stage of the progress.
} 
This offspring is generated, it would seem, by earnest dialectical discussion (accompanied, no doubt, by a good deal of besotted gazing, and perhaps some chaste caresses). How on earth, one wonders, would this work out in practice? Well, we actually do have two examples to go on, and we should take due note of them. One is Socrates' elenchus of young Lysis in the Lysis, where Socrates is explicitly giving Lysis' lover Hippothales a lesson in how to approach a beloved. This eventuates in a pretty austere and discouraging discussion on the nature of friendship, but Lysis appears to enjoy the experience (at least at Socrates' hands; it remains doubtful how much of this sort of thing he would have taken from Hippothales), and it may stand as one example of the sort of logoi in which a philosophic lover might indulge. The ultimate object, which is only very imperfectly realised in the dialogue as we have it, would be to bring the beloved to a higher state of consciousness, but we can see, I think, that Lysis has been started on a process of critical self-examination before he is hustled away home by his paidagōgos.

The other notable example, which attained particular fame in later antiquity (though its Platonic authorship is actually doubtful), ${ }^{9}$ is the Greater Alcibiades, where Socrates gives the young and bumptious Alcibiades a thorough going-over on his announcement that he is thinking of going into politics, showing him that he has not attained a proper degree of self-knowledge, such as would qualify him to attempt to guide others. Here, unlike in the case of the Lysis, Socrates is quite explicit that he is a lover of Alcibiades, and that it is in this capacity that he is moved to address him. It is significant that this dialogue was chosen in later antiquity as the proper introduction to any course of Platonism, and Socrates' role as portrayed in it was taken as paradigmatic of how a philosophic lover should approach his beloved. ${ }^{10}$

We do, then, have some notion as to how a Platonic sage was expected to behave when he had fallen prey to the arrows of Cupid. Presumably if he fell in with a kindred spirit among the young and beautiful, the relationship flourished; if not, not. In the handbooks on the Art of Love composed in later times by Stoics and Platonists, such as those of Cleanthes and Chrysippus, ${ }^{11}$ great stress was placed on the selection

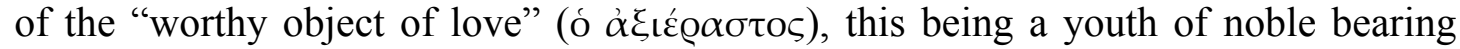
and virtuous disposition who would receive the advances of the sage, not with an irreverent raspberry, but with the respect and reverence that they deserved. The prescriptions as to how to approach the beloved, how to hold his attention, and how to make sure that one's love will be returned, all seem to be based, interestingly, not on the Symposium or the Phaedrus, as we would expect, but rather on the Alcibiades, and the reason, I think, is that only in the Alcibiades is the essential benevolence of the sage and his concern for the welfare of the beloved, rather than for his own spiritual advantage, properly brought out. Ancient thinkers, like ourselves, were made somewhat uncomfortable by the rampant self-centredness emanating from the pages of those two more famous dialogues.

To return, then, to our original paradox: love is a form of madness, which should be something antithetical to the life of reason advocated by Plato, but yet it is something that in Plato's view the philosopher must embrace wholeheartedly, if he is to attain

\footnotetext{
${ }^{9}$ I partake in this doubt, I must say, though I would regard the Alcibiades I as at least a product of the Old Academy, and thus largely relevant to our theme.

10 Cf. e.g. Hermeias, In Phdr. 207, 17ff. Couvreur, and see my article, 'A Platonist Ars Amatoria?', Classical Quarterly 44 (1994), 387-92 (repr. in Dillon, The Great Tradition: Further Studies in the Development of Platonism and Early Christianity, Aldershot: Variorum, 1997).

11 SVF I . 481; 3. 717.
} 
any degree of insight into the truth. Now Plato, of course, was a bachelor of generally very sober habits, but we can also observe, I think, from a number of the passages quoted earlier that he was a passionate man. ${ }^{12}$ The Phaedrus in particular may be seen as an attempt to reconcile these two aspects of his nature.

Prof. John Dillon

Trinity College Dublin, School of Classics

E-mail:dillonj@tcd.ie

12 As a footnote to this discussion, it is relevant to note, I think, that Plato does seem to have had at least one important love in his life, and that is Dion of Syracuse. When they first met in 389, at the court of Dionysius I, Plato was almost forty, and Dion was about twenty, and he obviously fulfilled most of the requirements for a Platonic beloved. The relationship continued up to Dion's death in 354 (murdered, in fact, by a renegade member of the Academy, Callippus), and no doubt flourished during Dion's sojourn in Athens in the 360's, when he was closely associated with the Academy. 